\title{
RELEASE OF VASOPRESSIN FROM ISOLATED PERMEABILIZED NEUROSECRETORY NERVE TERMINALS IS BLOCKED BY THE LIGHT CHAIN OF BOTULINUM A TOXIN
}

\author{
G. Dayanithi, ${ }^{* \dagger} \dagger$ G. Ahnert-Hilger, ${ }^{*}$ U. Weller, $\ddagger$ J. J. Nordmann $\S$ and M. Gratzl* \\ *Abteilung Anatomie und Zellbiologie der Universität Ulm, D-7900 Ulm, F.R.G. \\ $\ddagger$ Rudolf Buchheim Institut für Pharmakologie der Justus Liebig Universität, D-6300 Giessen, F.R.G. \\ $\S$ Centre de Neurochimie du CNRS, 5 rue Blaise Pascal, F-67084 Strasbourg, France
}

\begin{abstract}
The intracellular action on exocytosis of botulinim A toxin and constituent chains was studied using permeabilized isolated nerve endings from the rat neural lobe. The release of the neuropeptide vasopressin was measured by radioimmunoassay. In the presence of the reducing agent dithiothreitol, the two-chain form of botulinum $A$ toxin inhibited vasopressin release induced by $10 \mu \mathrm{M}$ free calcium. Half maximal inhibition was obtained with $15 \mathrm{nM}$ botulinum A toxin. In the absence of the heavy chain the light chain of the toxin strongly inhibited exocytosis with a half maximal effect of $2.5 \mathrm{nM}$. The inhibitory effects on secretion could be prevented by incubating the light chain with an immune serum against botulinum A toxin. The heavy chain of botulinum A toxin did not affect vasopressin release. However, it prevented the inhibitory effects of the light chain on stimulated exocytosis.

It is concluded that botulinum A toxin inhibits the calcium-dependent step leading to exocytosis by interfering with a target present in the isolated and permeabilized nerve terminals. The functional domain of this neurotoxin, which is responsible for the inhibition of vasopressin release, is present in its light chain.
\end{abstract}

Botulinum A toxin belongs to a family of closely related neurotoxins. The $150,000 \mathrm{~mol}$. wt protein consists of a heavy chain $(100,000 \mathrm{~mol}$. wt) and a light chain $(50,000 \mathrm{~mol}$. wt) covalently linked by a disulfide bond. It inhibits neurotransmission at the peripheral cholinergic nerve endings by inhibiting neurotransmitter release. A three-step model is thought to produce the paralytic effects. It consists of (i) extracellular binding, (ii) internalization and (iii) intracellular poisoning (cf. Refs 12 and 19). The toxins' effects are restricted to the nervous tissue when given extracellularly. However, an extracellular application does not allow the differentiation of the intracellular processes involved in the final inhibition of transmitter release and the role played by the individual chains of the toxin.

Recently, using cultured adrenal chromaffin cells permeabilized with streptolysin $O$, it has been shown that intracellularly applied botulinum $A$ toxin is more effective in the presence of a reducing agent. Indeed, the light chain of botulinum $A$ toxin alone inhibited $\mathrm{Ca}^{2+}$-stimulated catecholamine release. ${ }^{5,20,21}$ In contrast, both the heavy and the light chain must be

†Present address: Centre de Neurochimie du CNRS, 5 rue Blaise Pascal, F-67084 Strasbourg, France.

Abbreviations: AVP, arginine vasopressin; DTT, dithiothreitol; EGTA, ethyleneglycol-bis $\left(\beta\right.$-amino-ethylether) $N, N^{\prime}$ tetraacetic acid; HEPES, $N$-2-hydroxyethylpiperazine$N^{\prime}$-2-ethane sulfonic acid; PIPES, piperazine- $N, N^{\prime}$-bis(2-ethane sulfonic acid). present in Aplysia neurons to inhibit transmitter release. ${ }^{16}$ So far it is unknown whether these discrepancies are due to a general difference in the exocytotic mechanism in neurons as compared to endocrine cells or to differences between molluscs and mammals.

To address some of these questions, the nerve terminals isolated from the rat neural lobe were used as a mammalian neuronal system. These nerve endings represent a potent tool for studying the mechanism of stimulus-secretion coupling. ${ }^{14}$ They can be successfully permeabilized with digitonin and addition of micromolar amounts of $\mathrm{Ca}^{2+}$ are then sufficient to elicit neurohormone release. ${ }^{9}$ This process requires magnesium and chloride ions but not exogenous ATP. ${ }^{10}$ The permeabilized nerve terminals survive even prolonged incubations and are therefore suitable for studies with the slowly acting neurotoxins.

\section{EXPERIMENTAL PROCEDURES}

Preparation of isolated neurosecretory nerve terminals

The neural lobes were isolated from male Wistar rats (Charles River, Sulzfeld, F.R.G.) weighing 250-300 g and washed with normal Locke saline containing (in $\mathrm{mM}$ ): $\mathrm{NaCl}$ (140); $\mathrm{KHCO}_{3}$ (5); $\mathrm{MgCl}_{2}$ (1); $\mathrm{CaCl}_{2}$ (2.2); Tris-HEPES (10); glucose (10); bovine serum albumin (Miles) $0.025 \%$, pH 7.25. The medium was then replaced by a buffer containing $270 \mathrm{mM}$ sucrose, $10 \mathrm{mM}$ Tris-HEPES, $2 \mathrm{mM}$ EGTA instead of $0.01 \mathrm{mM}$ EGTA as described previously. ${ }^{8}$ The nerve endings were then isolated as described ${ }^{8}$ with some minor modifications. Briefly, the neurohypophyses were homogenized in the buffered sucrose solution and 
centrifuged at $100 \mathrm{~g}$ for $1 \mathrm{~min}$. The supernatant was taken and centrifuged again at $2400 \mathrm{~g}$ for $5 \mathrm{~min}$. The pellet contains mostly isolated nerve endings as judged by electron microscopy. ${ }^{15}$ Throughout the isolation procedure and the experiment the temperature was maintained at $37^{\circ} \mathrm{C}$. The nerve endings were then resuspended in normal Locke solution and loaded onto $0.20 \mu \mathrm{m}$ Gelman filters (Acro, LC 13) and perfused as given below.

\section{Superfusion of the isolated nerve endings}

The isolated nerve endings were perfused by means of a multichannel peristaltic pump (Ismatec IPN 8) for $60 \mathrm{~min}$ with normal Locke at a flow rate of $50 \mu 1 / \mathrm{min}$ which was then increased to $100 \mu \mathrm{l} / \mathrm{min}$ until the end of the experiment. The perfusion was further continued with normal Locke containing no $\mathrm{Ca}^{2+}$ but $5 \mathrm{mM}$ EGTA for $10 \mathrm{~min}$. The medium was then replaced by $\mathrm{K}^{+}$-glutamate buffer (medium B) containing (in $\mathrm{mM}$ ): $\mathrm{K}^{+}$-glutamate (130); $\mathrm{MgCl}_{2}$ (2); EGTA (5); glucose (10); PIPES [piperazine$N, N^{\prime}$-bis(2-ethane sulfonic acid)] (20); bovine serum albu$\min 0.025 \%$, pH 6.8 and perfusion-run for a further $30 \mathrm{~min}$. For permeabilization, the nerve endings were perfused for 5 min with $1 \mu \mathrm{M}$ digitonin in medium B. Subsequently, the terminals were perfused for $25 \mathrm{~min}$ with the various forms of botulinum A toxin dissolved in medium B supplemented with $1 \mathrm{mM}$ dithiothreitol (DTT). Stimulation was performed for $10 \mathrm{~min}$ with medium $B$ supplemented with $10 \mu \mathrm{M}$ free $\mathrm{Ca}^{2+}$. Collection of the perfusate by means of a fraction collector (Gilson-203) started $130 \mathrm{~min}$ after loading, i.e. 6 min before the $\mathrm{Ca}^{2+}$ stimulation. Fractions were collected every $2 \mathrm{~min}$ and immediately frozen until radioimmunoassay for released arginine vasopressin (AVP) was performed. ${ }^{7}$ The $\mathrm{Ca}^{2+}$ evoked hormone release was calculated by subtracting the mean basal release determined in the fractions preceding the onset of the $\mathrm{Ca}^{2+}$ stimulus from the amount of hormone found in each of the following eight fractions. ${ }^{8}$ Free $\mathrm{Ca}^{2+}$ concentrations were calculated using the stability constants listed ${ }^{18}$ and measured with a $\mathrm{Ca}^{2+}$ sensitive electrode ${ }^{4}$ as described recently. ${ }^{11}$

\section{Materials}

Botulinum A toxin (two-chain form), as obtained from Batelle Institute, Frankfurt, F.R.G., was homogeneous on SDS gel electrophoresis. It was separated into its heavy and light chain by high performance liquid chromatography anion exchange chromatography using a modification of the low performance liquid chromatography procedure described. ${ }^{17}$ All steps were performed at $18^{\circ} \mathrm{C}$ at $\mathrm{pH} 8.4$ (adjusted with $\mathrm{NaOH}$ ). Typically $600 \mu \mathrm{g}(1 \mathrm{ml})$ botulinum A toxin was first desalted on a Econo-Pac 10GD (Bio-Rad) column and then applied to a Mono Q 5/5 (PharmaciaLKB) column both equilibrated with buffer I containing (in $\mathrm{mM}$ ): $\mathrm{Na}_{2} \mathrm{~B}_{4} \mathrm{O}_{7}$ (7.5) and $\mathrm{NaH}_{2} \mathrm{PO}_{4}$ (15). The Mono $\mathrm{Q}$ column was washed with $6 \mathrm{ml}$ of buffer. For chain separation $50 \mathrm{mM}$ DTT dissolved in $1.5 \mathrm{ml}$ of buffer I was applied to the column and the flow was stopped for $2 \mathrm{~h}$. The light chain was then eluted at a rate of $0.25 \mathrm{ml} / \mathrm{min}$ with $7.5 \mathrm{ml}$ of a mixture of nine parts buffer II (buffer II supplemented with $2 \mathrm{M}$ urea and $50 \mathrm{mM}$ DTT) and one part of buffer III containing (in mM): $\mathrm{Na}_{2} \mathrm{~B}_{4} \mathrm{O}_{7}$ (75); $\mathrm{NaH}_{2} \mathrm{PO}_{4}$ (150); urea (2000); DTT (50). The absorbed heavy chain was finally eluted from the column with $7.5 \mathrm{ml}$ of buffer III. Fractions were collected and the chains were located using a protein assay. ${ }^{6}$ Immediately after separation the chains were dialysed against a $\mathbf{K}$-glutamate buffer containing (in $\mathrm{mM}$ ): $\mathrm{K}^{+}$-glutamate (150); PIPES (10); EGTA (0.5); nitrilotriacetic acid (5), pH 7.2 supplemented with 1 or $5 \mathrm{mM} \mathrm{DTT.}$ Toxicity $\left(\mathrm{LD}_{50}\right.$, s.c. in mice) was $1 \mathrm{ng} / \mathrm{kg}$ for the two-chain form and between 1 and $5 \mu \mathrm{g} / \mathrm{kg}$ for the separated heavy or light chains, respectively. Botulinum $\mathrm{A}$ antitoxin, an immune serum from horse $\mathrm{cg} 750 \mathrm{IU} / \mathrm{ml}$, was obtained from Behring Werke Marburg, F.R.G., and dialysed against $\mathrm{K}$-glutamate buffer before use.

\section{RESULTS}

When added to permeabilized neurosecretory nerve terminals the two-chain form of botulinum $A$ toxin decreased the $\mathrm{Ca}^{2+}$-evoked vasopressin release within $25 \mathrm{~min}$. Inhibition started at botulinum A toxin concentrations below $5 \mathrm{nM}$. The presence of a reducing agent, DTT, was required for the inhibitory effect of the two-chain form of botulinum A toxin. In the absence of DTT almost no inhibition occurred. Fifty per cent inhibition was achieved with around $15 \mathrm{nM}$ toxin (Fig. 1).

The isolated light chain of botulinum A toxin alone is fully active in these permeabilized nerve endings (Fig. 2). Incubation for a period of $25 \mathrm{~min}$ in the absence of free $\mathrm{Ca}^{2+}$ reduced the basal release only slightly. However, compared to the controls, the $\mathrm{Ca}^{2+}$-induced AVP release was strongly inhibited by the botulinum A toxin. The permeabilized terminals did not respond to a second $\mathrm{Ca}^{2+}$ challenge given after $50 \mathrm{~min}$ washout with $\mathrm{Ca}^{2+}$-free solution. This indicates that the effect of botulinum A toxin light chain was irreversible. Under the same conditions the controls fully responded to $\mathrm{Ca}^{2+}$ (Fig. 2).

The inhibitory effect of botulinum A toxin light chain on stimulated AVP release could be fully overcome by preincubating the light chain with an immune serum against botulinum $A$ toxin, indicating its specific action. The antiserum itself did not interfere with the basal or evoked AVP release (Fig. 3).

In order to find out whether the light chain alone is responsible for the observed effects or whether the heavy chain modifies the action of light chain, light and heavy chains were applied simultaneously.

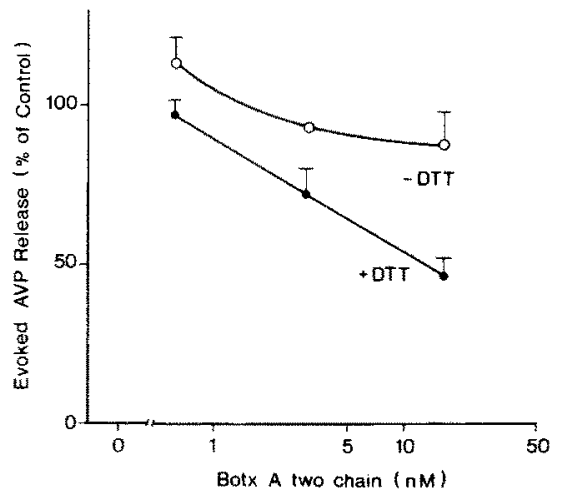

Fig. 1. Dose-response curve of botulinum A toxin (twochain form) on evoked AVP release from permeabilized nerve terminals in the presence or absence of $1 \mathrm{mM}$ DTT. Permeabilized nerve terminals were incubated for $25 \mathrm{~min}$ at $37^{\circ} \mathrm{C}$ with various amounts of botulinum $\mathrm{A}$ two-chain form (abscissa) in the absence (O) or presence (O) of $1 \mathrm{mM}$ DTT. Values are expressed as percentage of the AVP release evoked by $10 \mu \mathrm{M} \mathrm{Ca}^{2+}$. The values obtained in the presence of botulinum $A$ toxin are the mean of three experiments $\pm S$.E. The mean of $\mathrm{Ca}^{2+}$-evoked release from six individual experiments is taken as $100 \%(1667 \pm 185 \mathrm{pg}$ AVP relased during $\mathrm{Ca}^{2+}$ stimulation). 


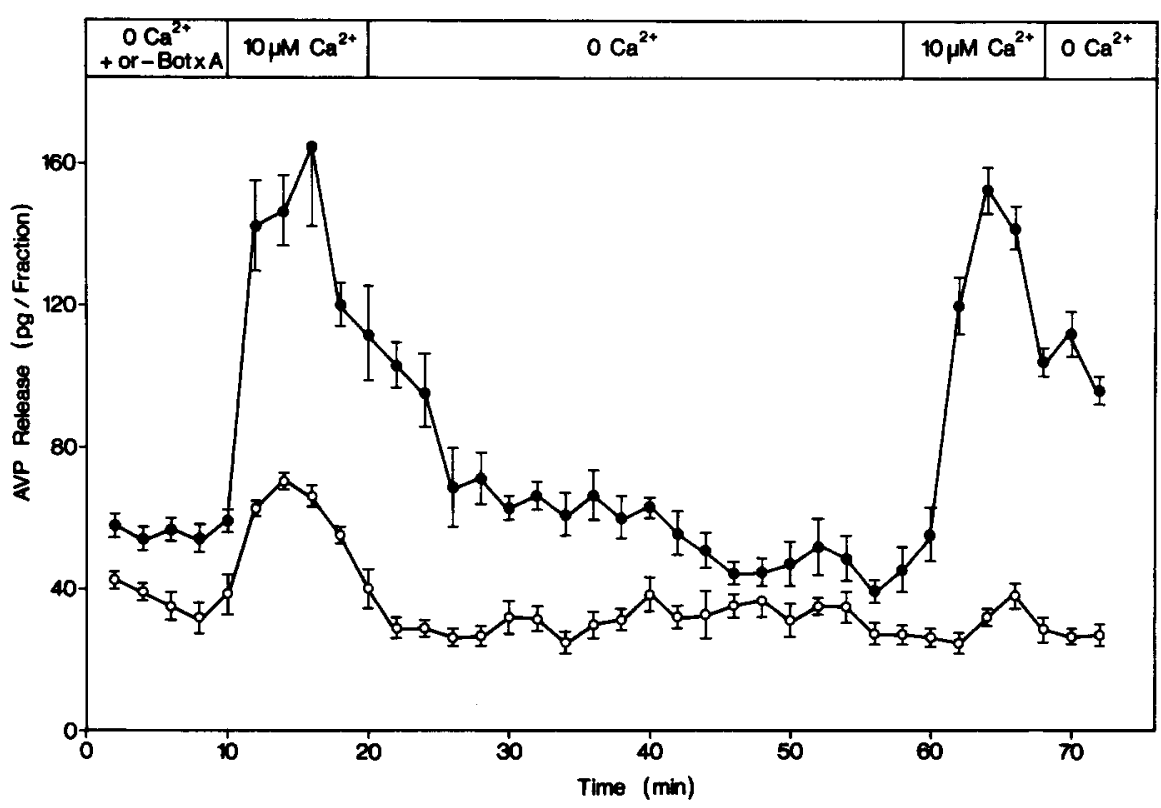

Fig. 2. Time course of AVP secretion from digitonin permeabilized isolated nerve terminals in the presence or absence of the light chain of botulinum A toxin. The isolated nerve terminals were perfused with buffer (medium B). After permeabilization they were preincubated with or without $3.3 \mathrm{nM}$ botulinum toxin A light chain for $25 \mathrm{~min}$. The nerve endings were then challenged with $10 \mu \mathrm{M}$ free $\mathrm{Ca}^{2+}$ for $10 \mathrm{~min}$. After a 50 min washout in the absence of $\mathrm{Ca}^{2+}$ the nerve endings were challenged again with $10 \mu \mathrm{M}$ free $\mathrm{Ca}^{2+}$ for $10 \mathrm{~min}$. The concentration of AVP was measured in each fraction $(2 \mathrm{~min})$. The closed circles represent the hormone release from control preparations and the open circles that from toxin-treated nerve terminals. Values are expressed as means \pm S.E. of four experiments.

Interestingly, the combined addition of the two chains either applied in equimolar concentrations (Fig. 4a) or with a ten-fold excess of the heavy chain (Fig. 4b) overcame the inhibitory action of $1 \mathrm{nM}$ light chain (Fig. 4a,b). The heavy chain alone did not alter basal or evoked AVP release (Fig. 4a,b). This result

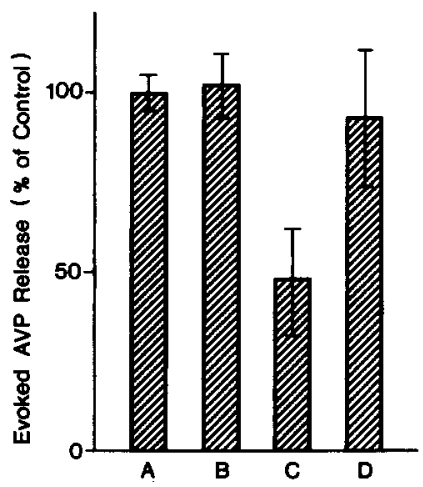

Fig. 3. Specificity of the inhibitory effect of botulinum A toxin light chain on stimulated AVP release from permeabilized nerve terminals. The experimental procedure was the same as in Fig. 2. The permeabilized nerve terminals were either preincubated with buffer (A), or with buffer containing $7.4 \mathrm{IE} / \mathrm{ml}$ antitoxin, an immune serum from horse (B), or with $1.8 \mathrm{nM}$ light chain (C) or $1.8 \mathrm{nM}$ light chain plus $7.4 \mathrm{IE} / \mathrm{ml}$ antitoxin (D) prior to the addition of $10 \mu \mathrm{M}$ $\mathrm{Ca}^{2+}$. The $\mathrm{Ca}^{2+}$ evoked AVP release (percentage of control) within $10 \mathrm{~min}$ (corresponding to the first challenge in Fig. 2) is given as the mean of four experiments \pm S.E. Onehundred per cent of vasopressin release (column $A$ ) is the mean of four individual experiments $(613 \pm 30 \mathrm{pg}$ AVP release during $\mathrm{Ca}^{2+}$ stimulation). is in accordance with experiments performed with the two-chain form in the presence of DTT, where $1 \mathrm{nM}$ botulinum A toxin did not inhibit AVP release

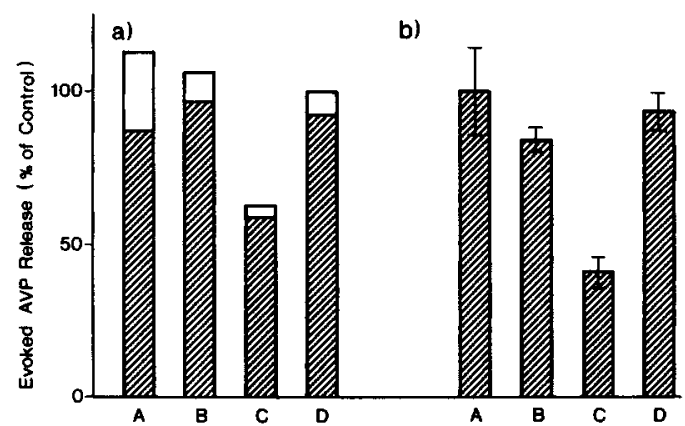

Fig. 4. Addition of botulinum A toxin heavy chain overcomes the inhibitory action of light chain on the AVP release from permeabilized nerve terminals. Two sets of experiments were performed in the presence of $1 \mathrm{mM}$ DTT as outlined in Fig. 3. In the left panel (a) the heavy and the light chain (each about $1 \mathrm{nM}$ ) were applied to the permeabilized nerve terminals either alone or after previous combination. In the right panel (b) the same amount of light chain ( $1 \mathrm{nM}$ ) but $10 \mathrm{nM}$ heavy chain was used. The nerve terminals have been incubated with medium $B$ before stimulation (A), with the heavy chain (B), with the light chain (C), and with both the heavy and the light chain (D). Values represent the $\mathrm{Ca}^{2+}$-evoked AVP release (percentage of control) of either two (a) or four \pm S.E. (b) experiments. Note that under either condition the heavy chain does not change the stimulated AVP release, but overcomes the inhibitory action of the light chain. One-hundred per cent represents $1180 \mathrm{pg}$ AVP released during $\mathrm{Ca}^{2+}$ stimulation in (a), and $445 \pm 64 \mathrm{pg}$ in (b). 


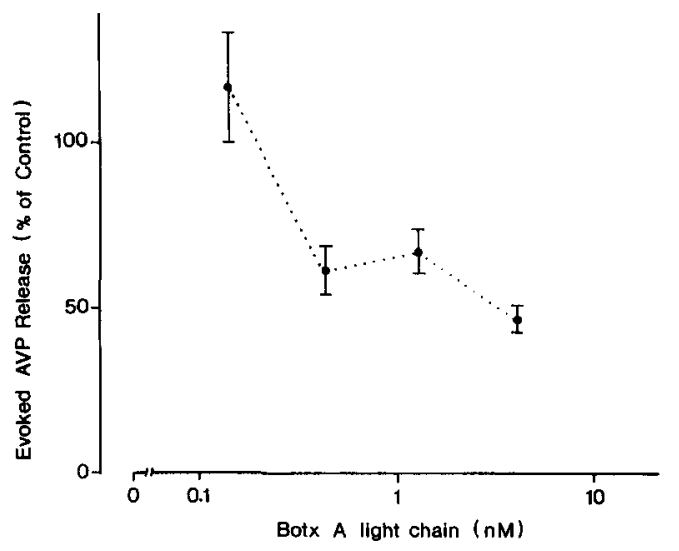

Fig. 5. Dose-response curve of the inhibitory effect of botulinum A toxin light chain on stimulated AVP release from permeabilized nerve terminals. Permeabilized nerve terminals were preincubated with increasing amounts of botulinum A toxin light chain (abscissa) as in Fig. 1. $\mathrm{Ca}^{2+}$-evoked AVP release is expressed as percentage of control. The values are expressed as the mean of three experiments $\pm S$.E. The mean $\mathrm{Ca}^{2+}$-evoked release from the six control experiments is taken as $100 \%(2249 \pm 56 \mathrm{pg})$.

(cf. Fig. 1 with Fig. 4). Thus, the heavy chain of botulinum A toxin does not contribute to the intracellular action of the light chain but rather inhibits it.

Figure 5 gives the dose-response curve of the inhibitory action of the light chain of botulinum $A$ toxin on evoked AVP release from permeabilized nerve terminals. The inhibition started below a light chain concentration of $1 \mathrm{nM}$. The evoked AVP release was inhibited by $50 \%$ after application of $2.5 \mathrm{nM}$ light chain for $25 \mathrm{~min}$ preceding the stimulation (Fig. 5).

Even higher doses of the light chain did not give complete inhibition of AVP release. This observation is in agreement with the situation seen in permeabilized chromaffin cells. ${ }^{21}$

\section{DISCUSSION}

The regulation of neurotransmitter release from mammalian synaptic terminals is poorly understood. Neurohypophysial nerve endings are an exception because they can be permeabilized and the intraterminal regulation of exocytosis can be analysed. ${ }^{9,14}$ We have used them to investigate the mechanism of neurotoxin action focussing on clostridial neurotoxins. ${ }^{12.19}$ Here we present the first report upon intracellular effects of botulinum $A$ toxin in a mammalian neuron.

We found that the two-chain form of botulinum $A$ toxin is more effective in the presence of a reducing agent, suggesting that the disulfide bridge which links the heavy and the light chain has to be cleaved before exocytosis is inhibited. More importantly, the light chain alone is fully active and more potent in inhibiting neurohormone release as compared to the reduced two-chain form. The action of botulinum $A$ toxin in permeabilized nerve terminals is in line with recent observations on streptolysin $\mathrm{O}$ permeabilized bovine adrenal chromaffin cells. ${ }^{20,21}$ In these neuroendocrine cells reductive conditions enhance the inhibitory effect on catecholamine secretion of the two-chain form of botulinum $\mathrm{A}$ toxin. ${ }^{20}$ Furthermore, the light chain alone is fully active..$^{5,21}$

The data also fit with a more general concept of clostridial neurotoxin processing. The primary gene product, a single chain form, has to be cleaved proteolytically and this is followed by a reduction of the interchain disulfide bond. As a consequence the light chain is activated. Recent results obtained with the closely related tetanus toxin in permeabilized adrenal chromaffin and PC12 cells are along this line. The single chain form is ineffective, the potency of the two-chain form is increased by a reducing agent and the light chain alone is fully inhibitory. ${ }^{1-3}$

Once in a cytosolic compartment the heavy chain which may be necessary for internalization is no longer required for full activity of the light chain. Moreover, if heavy and light chains are simultaneously present they are less active than the light chain alone. Again the situation resembles the one seen within chromaffin cells. Here the heavy chain does not change or rather reduces the potency of the light chains of botulinum $\mathrm{A}$ toxin $^{21}$ or tetanus toxin. 1

By contrast, in invertebrate neurons, such as those of the buccal ganglia of Aplysia, the roles of the chains are different. When directly injected into the neuron the light chain of botulinum $A$ toxin is not active on its own but requires the presence of a heavy chain. ${ }^{16}$ The presence of both chains of botulinum A toxin is unique since the light chain of tetanus toxin alone inhibits neurotransmitter release in Aplysia neurons. $^{13}$

The differences in botulinum $\mathrm{A}$ toxin action between Aplysia neurons and mammalian neuronal or chromaffin cells needs further investigation. One important difference to the mammalian systems is the high osmolarity of the medium required for studies with Aplysia neurons. Tnis might alter the conformation of the light chain of botulinum $A$ toxin or its target. The addition of the heavy chain may then help the light chain to become effective. However, it is not excluded that the exocytosis of the large granules from mammalian nerve terminals and that of small synaptic vesicles from Aplysia neurons is regulated differently.

Taken together the data presented here and those already published suggest that botulinum $\mathrm{A}$ toxin by its light chain attacks a step during exocytosis which is common to mammalian neurons and chromaffin cells. The precise localization of its attack, probably the vesicular or the plasma membrane, remains to be found.

Acknowledgements-The authors would like to thank Mrs M. Dreyer and Mrs M. Hudel for expert technical 
assistance and Dr John Bicknell (Babraham, Cambridge, U.K.) for AVP antiserum. G. Dayanithi is a fellow of the Alexander von Humboldt Foundation, F.R.G. This work was supported by the Deutsche Forschungsgemeinschaft (Gr 681), the Sonderforschungsbereich 249 , and grants from INSERM and CNRS, France.

\section{REFERENCES}

1. Ahnert-Hilger $G$., Bader M. F., Bhakdi S. and Gratzl M. (1989) Introduction of macromolecules into bovine adrenal medullary chromaffin cells and rat pheochromocytoma cells (PC 12) by permeabilization with streptolysin $\mathrm{O}$ : inhibitory effect of tetanus toxin on catecholamine secretion. J. Neurochem. 52, 1751-1758.

2. Ahnert-Hilger G., Weller U., Dauzenroth M. E., Habermann E. and Gratzl M. (1989) The tetanus toxin light chain inhibits exocytosis. Fedn Eur. biochem. Socs Lett. 242, 245-248.

3. Ahnert-Hilger G., Dauzenroth M. E., Habermann E., Henschen A., Kriegelstein K., Mauler F. and Weller U. (1990) Chains and fragments of tetanus toxin, and their contribution to toxicity. $J$. Physiol., Paris (in press).

4. Ammann D., Bührer T., Schefer U., Müller M. and Simon W. (1987) Intracellular neutral carrier-based Ca ${ }^{2+}$ microelectrode with subnanomolar detection limit. Pflügers Arch. ges. Physiol. 409, 223-228.

5. Bittner M. A., DasGupta B. R. and Holz R. W. (1989) Isolated light chains of botulinum neurotoxin inhibit exocytosis. J. biol. Chem. 264, 10354-10360.

6. Bradford M. M. (1976) A rapid and sensitive method for quantitation of microgram quantities of protein utilizing the principle of protein-dye binding. Analyt. Biochem. 72, 248-254.

7. Cazalis M., Dayanithi G. and Nordmann J. J. (1985) The role of patterned burst and interburst interval on the excitation-coupling mechanism in the isolated rat neural lobe. J. Physiol., Lond. 369, 45-60.

8. Cazalis M., Dayanithi G. and Nordmann J. J. (1987) Hormone-release from isolated nerve endings of the rat neurohypophysis. J. Physiol., Lond. 390, 55-70.

9. Cazalis M., Dayanithi G. and Nordmann J. J. (1987) Requirements for hormone release from permeabilized nerve endings isolated from the rat neurohypophysis. $J$. Physiol., Lond. 390, 71-91.

10. Dayanithi G. and Nordmann J. J. (1989) Chloride and magnesium dependence of vasopressin release from rat permeabilized neurohypophysial nerve endings. Neurosei. Lett. 106, 305-309.

11. För K. J., Warchol W. and Gratzl M. (1990) Calculation and control of free divalent cations in solutions used for membrane fusion studies. Meth. Enzym. (in press).

12. Habermann E. and Dreyer F. (1986) Clostridial neurotoxins: handling and action at the cellular and molecular level. Curr. Topics Microbiol. Immun. 129, 93-179.

13. Mochida S., Poulain B., Weller U., Habermann E. and Tauc L. (1989) Light chain of tetanus toxin intracellularly inhibits acetylcholine release at neuro-neuronal synapses, and its internalization is mediated by heavy chain. Fedn Eur. biochem. Socs Lett. 253, 47-51.

14. Nordmann J. J., Dayanithi G. and Lemos J. R. (1987) Isolated neurosecretory nerve endings as a tool for studying the mechanism of stimulus-secretion coupling. Biosci. Rep. 7, 411-426.

15. Nordmann J. and Dayanithi G. (1988) The release of neuropeptides does not only occur at the nerve terminals. Biosci. Rep. 8, 471-483.

16. Poulain B., Tauc L., Maisey E. A., Wadsworth J. D. F., Mohan P. M. and Dolly J. O. (1988) Neurotransmitter release is blocked intracellularly by botulinum neurotoxin, and this requires uptake of both toxin polypeptide by a process mediated by larger chain. Proc. natn. Acad. Sci. U.S.A. 85, 4090-4094.

17. Sathyamoorthy V. and DasGupta B. R. (1985) Separation, purification, partial characterization and comparison of the heavy and light chains of botulinum neurotoxintypes A, B and E. $J$. biol. Chem. 260, 10,461-10,466.

18. Sillen L. G. and Martell A. D. (1971) Stability Constants of Metal Ion Complexes, Suppl. 1. The Chemical Society, London.

19. Simpson L. L. (1989) Peripheral actions of the botulinum toxins. In Botulinum Neurotoxin and Tetanus Toxin (ed. Simpson L. L.), pp. 153-178. Academic Press, New York.

20. Stecher B., Gratzl M. and Ahnert-Hilger G. (1989) Reductive chain separation of botulinum A toxin-a prerequisite to its inhibitory action on exocytosis in chromaffin cells. Fedn Eur. biochem. Socs Lett. 248, $23-27$.

21. Stecher B., Weller U., Habermann E., Gratzl M. and Ahnert-Hilger G. (1989) The light chain but not the heavy chain of botulinum A toxin inhibits exocytosis from permeabilized adrenal chromaffin cells. Fedn Eur. biochem. Socs Lett. 255, 391-394. 